\title{
EDUCAÇÃO RURAL EM PORTUGAL COMO OBJETO DE ESTUDO: POSSIBILIDADES DE ESPECIFICAÇÕES CONCEITUAIS (1990-2018) ${ }^{1}$
}

\author{
Flávio Reis Santos ${ }^{2}$ \\ Magda Valéria Silva ${ }^{3}$
}

\section{RESUMO}

Os objetivos do presente artigo são contextualizar a educação rural como objeto de estudo e apontar possíveis definições sobre a educação rural em Portugal no decurso da segunda metade do século XX para as duas primeiras décadas do século XXI. Para materializar o estudo, empreendemos revisão e análise da produção bibliográfica portuguesa sobre a temática, pois entendemos que os artigos científicos, teses, dissertações, livros e demais documentos constituem fonte inesgotável de informações, que proporcionam ao investigador examiná-las

1 Este artigo é parte constituinte do terceiro capítulo da pesquisa de pós-doutoramento intitulada "Educação rural: em busca de definições conceituais lato sensu (Brasil, Espanha e Portugal)", realizada no Programa de Pós-Graduação em Geografia da Universidade Federal de Goiás - Regional Catalão.

2 Universidade Estadual de Goiás (UEG), Anápolis/GO, Brasil.

3 Universidade Federal de Goiás (UFG), Goiânia/GO, Brasil. 
em profundidade para encontrar inconsistências e divergências sobre o objeto estudado. Constatamos que a educação rural deve ter por princípio o reforço dos vínculos de pertencimento e resistência das populações locais por meio de atividades educativas específicas para a efetiva construção do conhecimento, com vistas à promoção e garantia do direito à educação e escolarização, prática e disseminação das culturas e desenvolvimento econômico coletivo das populações rurais.

Palavras-chave: Portugal, educação rural, escola rural, resistência.

\title{
EDUCACIÓN RURAL EN PORTUGAL COMO OBJETO DE ESTUDIO: POSIBILIDADES DE ESPECIFICACIONES CONCEPTUALES (1990-2018)
}

\section{RESUMEN}

Los objetivos de este artículo son contextualizar la educación rural como objeto de estudio e identificar posibles definiciones de la educación rural en Portugal durante la segunda mitad del siglo XX a las dos primeras décadas del siglo XXI. Para materializar el estudio se realizó una revisión y análisis de la producción bibliográfica portuguesa sobre el tema, porque entendemos que los artículos científicos, tesis, disertaciones, libros y otros documentos constituyen una fuente inagotable de información, proporcionando el investigador le examine en profundidad para encontrar inconsistencias y divergencias sobre el objeto estudiado. La educación rural debe tener por principio el refuerzo de los vínculos de pertenencia y resistencia de las poblaciones locales por medio de actividades educativas específicas para la efectiva construcción del conocimiento, con miras a la promoción y garantía del derecho a la educación y escolarización, práctica y diseminación de las culturas y el desarrollo económico colectivo de las poblaciones rurales.

Palabras clave: Portugal, educación rural, escuela rural, resistencia.

\section{RURAL EDUCATION IN PORTUGAL AS STUDY OBJECT: POSSIBILITIES OF CONCEPTUAL SPECIFICATIONS (1990-2018)}

\begin{abstract}
The objectives of this article are to contextualize rural education as an object of study and to point out possible definitions about rural education in Portugal during the second half of the 20th century for the first two decades of the 21st century. In order to materialize the study, we undertake review and analysis of the Portuguese bibliographic production on the subject, since we understand that scientific articles, theses, dissertations, books and other documents are an inexhaustible source of information, which allows the investigator to examine them in depth to find inconsistencies and disagreements about the object studied. We note that rural education should have as principle the reinforcement of the bonds of belonging and resistance of local populations through specific educational activities for the effective construction of knowledge, with a view to promoting and guaranteeing the right to education and schooling, practice and dissemination of cultures and collective economic development of rural populations.
\end{abstract}


Keywords: Portugal, rural education, rural school, resistance.

\section{L'EDUCATION RURALE AU PORTUGAL EN TANT QU'OBJET D'ÉTUDE: POSSIBILITES DE SPECIFICATIONS CONCEPTUELLES (1990-2018)}

\section{RESUME}

Les objectifs de cet article sont de contextualiser l'éducation rurale en tant qu'objet d'étude et de préciser les définitions possibles de l'éducation rurale au Portugal au cours de la seconde moitié du XXe siècle et des deux premières décennies du XXIe siècle. Afin de concrétiser l'étude, nous entreprenons une revue et une analyse de la production bibliographique portugaise sur le sujet, car nous comprenons que les articles scientifiques, thèses, mémoires, livres et autres documents sont une source d'informations inépuisable, ce qui permet au chercheur de les examiner en profondeur pour trouver des incohérences et des désaccords sur l'objet étudié. Nous pouvons souligner que l'éducation rurale devrait avoir pour principe le renforcement des liens d'appartenance et la résistance des populations locales à travers des activités éducatives spécifiques pour la construction effective des connaissances, en vue de promouvoir et de garantir le droit à l'éducation et à la scolarisation, à la pratique et à la diffusion. des cultures et du développement économique collectif des populations rurales.

Mots-clés: Portugal, éducation rurale, école rurale, résistance. 


\section{INICIANDO A DISCUSSÃO}

O objeto do presente estudo é constituído pela educação e pela escola para as populações que residem no meio rural de Portugal e que foram relegadas ao esquecimento pelo Estado, visto que não houve qualquer delimitação sobre a temática no contexto de desconstrução, desagregação, degradação e subordinação do universo rural à ideologia urbanocêntrica do capitalismo, que lhe impôs e impõe a retirada dos "últimos sinais do reconhecimento da sua existência e da sua identidade como espaço social. Perda que reforça e aprofunda a crise quase generalizada do meio rural" (AMIGUINHO, 1996, p. 114). Considerando tal contexto, definimos os seguintes objetivos para o desenvolvimento deste estudo: 1) Contextualizar a educação rural como objeto de estudo em Portugal no transcorrer dos séculos XX e XXI; 2) Apontar possíveis definições que especifiquem a educação para as populações que habitam no meio rural português.

Iniciamos as nossas explanações apontando que, para os ideais da economia capitalista, sobretudo, até a primeira metade do século $\mathrm{XX}$, o meio rural tradicional constituiu um "irritante" empecilho e substancial oposição conservadora ao integral desenvolvimento de uma sociedade de mercado totalmente desimpedida de ação. Todavia, a implacável determinação do sistema sustentando pela perspicácia e competência da intelectualidade tecnocrática burguesa possibilitou - em razão do poder econômico - a absorção do universo rural a partir da segunda metade do século $\mathrm{XX}$ e, mais especificamente, na transposição do século XX para o século XXI, com a efetivação do processo de globalização do capitalismo, garantindo o pleno sucesso do mercado em âmbito mundial.

À medida que removeu as poucas barreiras que restringiam a sua efetiva expansão, o sistema capitalista transpassou fronteiras e regimes políticos nacionais, desconsiderou completamente culturas e civilizações, reterritorializou as relações capitalistas de produção por meio da ação efetiva de 
suas instituições e de seu vigor produtivo. A mecanização, maquinização, tecnificação e quimificação dos processos produtivos no universo rural foram tomados pelo binômio urbanização-industrialização, expresso como "modo de vida, padrões e valores socioculturais, secularização do comportamento e individualização" (IANNI, 1997, p. 13).

Nesse contexto, podemos afirmar, que praticamente todos os segmentos agropecuários foram submetidos à racionalização das atividades produtivas e à (re)organização técnica e social do trabalho com o objetivo de aumentar a produtividade, a produção de excedente, a mais-valia e o lucro do capitalista. "Os processos de concentração e centralização do capital em escala mundial revolucionaram as condições de vida e trabalho no campo, acelerando inclusive a urbanização como estilo de vida e modo de localizar-se no mundo" (IANNI, 1997, p. 41). No entanto, as significativas transformações decorrentes desses processos não resultaram em uma homogeneização da sociedade suficientemente capaz para extinguir em definitivo as características específicas e as particularidades gerais de determinadas territorialidades e de seus agrupamentos sociais.

$\mathrm{Na}$ apreensão de Maria Wanderley (2000, p. 92), o processo de crescimento e expansão das cidades se acelera e sua forma se transforma permanentemente, o que resulta no aumento das "punções sobre o universo rural - que afetam, inclusive, os próprios sistemas de produção e de comercialização -, intensificando o êxodo rural e as cidades passam a exercer um domínio financeiro, administrativo e cultural sobre o campo". Essas mudanças alteraram e continuam a alterar o modo de produção nas sociedades rurais tradicionais, que podem ser caracterizadas pela gradativa modernização do processo produtivo agrícola, maior integração e interação deste setor com o mercado interno e, sobretudo, com os mercados externos. O desenvolvimento industrial, por sua vez: 
[...] na medida em que se concentrou nos espaços urbanos reiterou a estreita identificação entre a atividade agrícola e o meio rural; [...] o lugar da agricultura no crescimento econômico se definiu pela sua importância para a acumulação do capital no quadro das políticas intersetoriais keynesianas, a política agrícola gerava para a indústria uma reserva de mão de obra e a expansão de novos mercados. Para responder à crise que resultou da estreita subordinação da agricultura, a legislação então adotada, expressou um compromisso institucional que, mesmo procurando atender às reivindicações referentes à paridade de renda, entre a agricultura e os demais setores, e, a uma maior participação dos sindicatos de agricultores nas instâncias administrativas de decisão, reafirmou aquela subordinação (WANDERLEY, 2000, p. 93-94, grifos originais).

Esse conjunto de transformações econômicas, sociais, geográficas e culturais impostas pelo desenvolvimento capitalista, assentado na industrialização e na urbanização da sociedade colaboraram para desestabilizar o meio rural e debilitar as atividades dos pequenos produtores agrícolas nas mais diversas partes do mundo, que vêm sofrendo nas últimas décadas a intensificação do êxodo rural. Em Portugal, o esvaziamento populacional do meio rural seguiu duas direções: inúmeras pessoas se encaminharam para as grandes cidades nacionais e, outras, para os centros urbanos de outros países europeus e americanos, reterritorializando o rural no máximo, em espaço exclusivo de moradia. Essas mudanças reverberaram diretamente na organização e funcionamento do sistema educacional e da escola para as populações que se mantiveram (mantêm) no meio rural, historicamente subordinado a uma concepção "desenvolvimentista” do meio urbano.

Nesse contexto, podemos afirmar, de um lado, que as populações rurais têm sido sistematicamente vitimadas pela desatenção, descaso e mesmo abandono do Estado, que em sintonia e obediência às políticas neoliberais emanadas dos organismos multilaterais internacionais - Bando Mundial (BM), Organização das Nações Unidas para a Educação, a Ciência e a Cultura (Unesco), Organização para a Cooperação e Desenvolvimento Econômico (OCDE) - se subordinam às concepções de racionalidade e racionalização na utilização de recursos materiais e imateriais, sobretudo, aqueles destinados à 
oferta e manutenção de serviços sociais básicos - educação, saúde, habitação, segurança, transporte etc. De outro lado, foi em decorrência de tais condições e situações, que as discussões sobre as populações que habitam no universo rural e suas necessidades escolares ganharam legitimidade, visto que passaram a fazer parte do discurso político-ideológico dos movimentos sociais rurais, sendo absorvidas pelo universo acadêmico-científico como unidade social inserida no sistema de produção capitalista na atualidade.

Antes de prosseguir com as nossas análises, entendemos ser pertinente esclarecer que a proposta inicial desta revisão bibliográfica se restringia à realização de uma verificação no Portal de Periódicos da Coordenação de Aperfeiçoamento de Pessoal de Nível Superior (Capes) dos artigos científicos publicados sobre a "educação rural" e a "escola rural" na perspectiva de identificar ou construir conceitos que definissem a educação para as populações rurais em Portugal. Iniciamos as nossas buscas utilizando o assunto "educação rural em Portugal" e busca refinada para "artigos" - obtivemos a indicação de 571 escritos -, refinamos novamente com "periódicos revisados por pares" e o retorno foi de 425 escritos; por fim, refinamos com "idioma português" e a quantidade selecionada foi de 25 escritos com as seguintes especificações:

- 13 artigos não se relacionavam com a educação; 5 artigos discutiam assuntos associados à educação e à saúde; os temas educação superior, educação de adultos, ensino básico, ensino primário e avaliação da educação, história da educação e história rural de Portugal contaram com um artigo cada. Nenhum artigo sobre a educação rural foi identificado, fato que nos causou grande estranheza e demandou a investigação em outras plataformas/bases de dados: recorremos ao Scientific Eletronic Library Online (Scielo) e o resultado mais uma vez foi decepcionante, ou seja, nenhum artigo identificado sobre o assunto;

Na segunda fase do processo de identificação dos artigos utilizamos o assunto "escola rural em Portugal", o resultado inicial foi de 755 artigos, empregamos o refinamento "artigos" e obtivemos o retorno de 626 escritos; na 
sequência refinamos mais uma vez a busca com "periódicos revisados por pares", que chegamos ao número de 540 escritos; utilizamos "idioma português" para realizar o último refinamento e obtivemos 34 escritos para verificação dos títulos e leitura dos respectivos resumos: 18 artigos não apresentam qualquer vinculação com a escola rural; 7 artigos tratavam de temas relacionados à educação e à saúde; 2 artigos diziam respeito ao desenvolvimento socioeconômico português; os temas escola distrital, escola e comunidade, escolaridade popular, ensino primário, ensino básico, educação física e história somaram 7 artigos, ou seja, um artigo para cada uma dessas temáticas.

Recorremos, mais uma vez, ao Scientific Eletronic Library Online (Scielo) e conseguimos identificar dois escritos que apresentavam por temática "a escola rural em Portugal": "A Escola Rural na Produção Acadêmica Portuguesa: Apontamentos sobre a (In)visibilidade de um Objeto de Estudo", publicado em 2016 pela Revista Portuguesa de Educação; e, "Representações Sociais da Escola Rural de Meados do Século XX em Portugal”, publicado em 2007 pela Revista Análise Psicológica. Este segundo artigo não se enquadrou na nossa perspectiva de estudo, visto que sua análise se concentrava essencialmente nas representações sociais produzidas por um grupo de pessoas nascidas entre os anos de 1926 e 1936 na região de Ferreira do Zêzere, parte constituinte do Distrito de Santarém (Província do Ribatejo).

Adentramos em uma terceira fase na busca de artigos sobre a educação rural e a escola rural em Portugal, agora no Google Scholar (Google Acadêmico), publicados no período de 1990 a 2017: o retorno inicial foi de 16.300 - extremamente amplo, na medida em que abarcou outras temáticas relacionadas direta e indiretamente à "educação", e, não ficou restrito a artigos publicados em periódicos científicos revisados por pares, pois teses, dissertações, trabalhos de conclusão de cursos e demais escritos foram disponibilizados. No processo de seleção chegamos a 7 artigos publicados em periódicos portugueses, espanhóis e brasileiros - Amiguinho (1996; 2008; 2011), Canário (2000), Cruz (2016), Magalhães (2013; 2018) -; 4 livros - Iturra 
(1990), Stoer \& Araújo (1992), Sarmento, Sousa \& Ferreira (1998), Sarmento \& Oliveira (2005) -; 2 teses - Amiguinho (2004), Oliveira (2005) -; 1 dissertação - Palmeiro (2011).

Cabe aqui ressaltar, por meio das palavras de Manuel Sarmento \& Joaquim Oliveira (2005, p. 91), que no universo rural se verifica "uma realidade de acumulação sedimental de vários tempos históricos, de várias formas de conceber a sociedade, de estabelecer relações sociais e de perspectivar a relação da educação e o espaço produtivo". Nesta direção, não é possível aceitar qualquer concepção homogeneizante que possa apreender a educação e suas "práticas educativas no mundo rural como se tratasse de um campo plano, sem relevos, sem contradições, sem tensões e sem ambiguidades", uma vez que, existe grande diversidade de "formas de agir e de realizar o processo educativo em contexto rural que é exatamente inerente a esta convergência de várias diacronias na mesma sincronia, a esta natureza sedimental, palimpséstica da realidade social" (SARMENTO; OLIVEIRA, 2005, p. 91).

Nesse sentido, complementamos que nos dias atuais, uma nova conformação do meio rural emerge a partir de novas possibilidades de interação e articulação com o meio urbano, constituindo novas formas e possibilidades de vida em comunidade, que encontra na educação para os rurícolas e na escola no meio rural uma perspectiva, um recurso, um instrumento de movimentação e promoção do desenvolvimento local inserido no capitalismo globalizado.

\section{EDUCAÇÃO E ESCOLA PARA AS POPULAÇÕES DO UNIVERSO RURAL}

Após analisar o contexto histórico da educação no primeiro terço do século XX, Romulo Carvalho (1996) argumenta que o fato de a massa populacional portuguesa ter acesso à alfabetização - de acordo com o entendimento do Estado português - se encontrava na sua "perigosa" utilização; 
ocorrência que levou os formuladores de leis - tecnocratas - a elaborar uma legislação voltada para a realização de um processo de formação escolar obrigatório com duração reduzida, sendo considerado ainda, que o acesso aos níveis superiores de ensino era privilégio de poucos, restringindo a ensinagem na educação primária à leitura, à escrita e às quatro operações matemáticas. Esse contexto histórico, de acordo com as inferências de Luiza Cortesão (1988, p. 68): "glorificava a ignorância, acompanhada da obediência, limpeza, ordem e pontualidade; assim como a poesia da pobreza e da vida rural, ao mesmo tempo em que se aproveita de todas as oportunidades para procurar reduzir as aspirações de promoção social através da educação".

Justino Magalhães (2018, p. 279), de sua parte, expõe que a Portugal da primeira metade do século $\mathrm{XX}$ permanecia fundamentalmente rural e as tentativas de reduzir o analfabetismo confundiu com frequência, "o ruralismo com arcaísmo e menoridade cívica”. Esta dicotomia, que remete as suas origens e desdobramentos à formação escolar para as populações do meio rural, decorria do embate entre a escola primária elementar/completar e os níveis subsequentes do processo de escolarização para as populações urbanas e a escola unitária, uma vez que:

\begin{abstract}
Os núcleos urbanos estavam, de uma forma geral, servidos de escolas elementares e, em alguns casos, complementares. A distinção entre urbano e rural acentuava-se na falta de oportunidade, na dificuldade de acesso, mas não necessariamente na desvalorização da formação escolar. Com efeito, também para os estratos da população mais empobrecidos, mesmo que urbanos e para uma parte significativa das populações rurais, o saber ler, escrever e contar quer obtido de modo informal quer através da frequência escolar, não se traduzia necessariamente numa melhoria de vida (MAGALHÃES, 2018, p. 279).
\end{abstract}

Nesses trilhos, materializa-se a criação de uma rede de escolas rurais para o ensino primário elementar integrada em uma moderada e contida administração dos recursos públicos, resultou na criação dos denominados 
"postos de ensino", consubstanciada na materialização de uma cultura suficientemente capaz de alfabetizar as crianças do universo rural em "perfeita" sintonia com os objetivos ideológicos em desenvolvimento, ou seja, os postos de ensino constituíram, de fato, muito "mais um instrumento da iniciativa da Ditadura em prol da [suposta] diminuição do número de iletrados" em terras portuguesas (RAMOS apud CARVALHO, 1996, p. 736).

A educação e a escola rurais portuguesas foram disseminadas por meio de uma ideologia que enaltecia a renúncia, a privação, a desistência e o derrotismo das populações que habitavam no meio rural, corporificada no amparo ao homem inculto e na incumbência de equilibrar um contingente de pessoas marcado por acentuadas desigualdades econômicas e sociais, evidenciadas pelo profundo descaso e não investimento do Estado na disponibilização de recursos suficientes para preparar técnica, intelectual e culturalmente as comunidades locais.

O rural como expressão do passado, da letargia, do atraso, como "realidade assimétrica endógena e contraposta ao urbano" alcançou e atravessou as décadas seguintes (1940, 1950, 1960) e, a ruralidade, por sua vez, permaneceu entendida - não apenas internamente pelos países pobres ou em desenvolvimento, mas externamente, sobretudo, por instituições multilaterais como a Organização das Nações Unidas para a Educação, a Ciências e a Cultura (UNESCO) e Organização para a Cooperação e Desenvolvimento Econômico (OCDE) - "como sinónimo de pobreza e conservadora das assimetrias sociais e das hegemonias internacionais” (MAGALHÃES, 2013, p. 71).

Nessa direção, o Estado português ao empregar uma fundamentação unitária e uma administração corporativa, visou deslindar as questões controversas entre os universos urbano e o rural, mantendo o ruralismo "nas economias regionais e na complementaridade orgânica. A escola era unitária, mas o professor, para além de ensinar deveria prosseguir a tarefa mobilizadora e morigeradora das populações rurais e levar ainda, alguma informação científica e técnica às populações” (MAGALHÃES, 2018, p. 283). 
As instituições multilaterais internacionais também influenciaram no contexto histórico da Espanha4, no qual as concepções acerca do rural e do urbano se assemelhavam àqueles verificados em Portugal, e, as políticas desenvolvidas no período exprimiam a discriminação caracterizada pela contradição entre a valorização da cidade e o desapego às questões do universo rural, na medida em que ressaltavam a satisfação das necessidades das áreas urbanas quanto à infraestrutura, urbanização, industrialização, serviços e equipamentos.

O deslocamento dessa contradição para o sistema educacional afirmava a prioridade dada pelo governo espanhol aos centros urbanos em detrimento da oferta e manutenção de serviços mínimos para as pequenas comunidades rurais (LUNA, 2010). A escola rural na Espanha ao longo da maior parte do século XX, considerada a sua localização espacial - áreas de difícil acesso -, com baixos níveis econômicos, sociais e culturais era sistematicamente colocada numa condição de subalternidade em relação à escola da cidade (HEREDERO; GONZÁLEZ; NOZU, 2014).

A escola no meio rural espanhol recebeu pouca atenção do Estado, que a classificava como escola de quarta categoria, escola de aldeia, escola de povoado. Essas denominações depreciativas, não teriam muita importância se não decorressem do desatino de que as escolas rurais são inferiores às escolas urbanas, pois dispõem de reduzidos recursos humanos e materiais, não oferecem os diferentes níveis de ensino e estão na agenda das necessidades educacionais do país.

Ao analisarmos a realidade brasileira, levando em conta os contextos que caracterizarm a relação urbano e rural, constatamos que os apontamentos efetuados por Luna (2010) e por Heredero, González \& Nozu (2014), muito se assemelham à concepção verificada nos países ibéricos, visto que o universo rural foi (é) "sistematicamente associado a uma concepção determinista e

\footnotetext{
4 Para atender parte das pressões externas, o governo espanhol publicou em 1970, a Lei Geral de Educação. Disponível em: http://www.boe.es/diario_boe/txt.php?id=BOE-A-1970-852LGE.
} 
discriminatória de atraso e retrocesso, ao mesmo tempo em que a cidade exprime a égide do desenvolvimentismo e da modernidade econômica na sociedade capitalista" (SANTOS; BEZERRA NETO, 2015, p. 179).

Na mesma direção, Leite (2002) argumenta, que a educação rural no Brasil tanto por razões sociais quanto culturais foi menosprezada e inferiorizada, tendo por fundo ideológico "o elitismo acentuado do processo educacional aqui instalado pelos jesuítas e a interpretação político-ideológica da oligarquia agrária conhecida popularmente na expressão: gente da roça não carece de estudos. Isso é coisa de gente da cidade”. Portanto, podemos afirmar convictamente que a educação rural e a escola rural em Portugal, na Espanha e no Brasil foram historicamente colocadas em segundo, terceiro ou quarto plano por seus respectivos governantes, orientados pela equivocada "crença" de que $o$ urbano representa o futuro, o desenvolvimento, o progresso, enquanto que o rural é a "expressão" do passado, da letargia, do retrocesso.

Retornemos às dificuldades econômicas e ao isolamento político de Portugal no interior do continente europeu, situação que na conformidade das orientações da OCDE e do Banco Mundial requeria a construção de um plano de ação que colocasse o país nos trilhos da industrialização e da mecanização do processo produtivo, pois, havia a urgência da realização de reformas no sistema educacional. Entretanto, a tímida preocupação política do Estado com a educação primária obrigatória para os moradores do meio rural no decurso da década de 1960, apesar das pressões externas sofreu um refreamento na medida em que os anos de escolaridade aumentaram, de acordo com o disposto nos Decretos-Lei n. 40.964/1957 e n. 42.944/1960. Esta ocorrência afetou em demasia as pequenas escolas e pequenas comunidades, espaços em que se verificava as negativas consequências das políticas públicas praticadas até então.

Diante das dificuldades, necessidades, incapacidades e insuficiências do Estado e do regime político português para empreender reformas consistentes na educação e com vista a aproximar-se das políticas que se desenvolviam nos 
outros países ocidentais, o então Ministro da Educação Francisco de Paula Leite Pinto (1955-1961) recorreu à OCDE para desenvolver um trabalho comum entre os técnicos portugueses, supervisionados e avaliados por especialistas da instituição multilateral internacional e com financiamento conjunto.

O staff tecnocrático da OCDE vislumbrou "uma grande oportunidade de influência na definição da política pública no sentido da ligação entre a educação e o crescimento econômico e, por extrapolação, o progresso social", estendendo o Projeto Regional do Mediterrâneo 5 para outros países que se encontravam em situação semelhante à portuguesa - Espanha, Grécia, Itália, Turquia e Iugoslávia -, ou seja, "apresentavam baixo rendimento per capita, elevada percentagem da população ativa na agricultura, falta de pessoal qualificado, baixas taxas de escolarização e carência de equipamentos escolares (LEMOS, 2014, p. 75 e 79).

A interferência direta da OCDE por meio do Plano Regional do Mediterrâneo determinou a direção das políticas públicas de educação em Portugal alinhado às carências da promoção do desenvolvimento econômico e social do país, na perspectiva de satisfazer as necessidades de mão de obra especializada até meados da década de 1980 . A constatação da necessidade de viabilizar o desenvolvimento socioeconômico português, reitera Alice Mendonça (2011), demandou a intensificação da escolarização de toda a população, pois somente assim seria possível colocar em marcha o processo desenvolvimentista de Portugal.

Chamamos a atenção para o contexto econômico mundial do período no qual se instalava a reorganização, a reordenação, o redirecionamento do sistema econômico capitalista, que resultou na desmontagem do Estado de Bem-Estar Social $^{6}$ e no restabelecimento dos fundamentos liberais clássicos de não

\footnotetext{
5 Em 1959/1960, a OCDE realizou avaliação diagnóstica a Portugal, propiciando o contexto adequado para o ministro da educação português solicitar ajuda para definir os objetivos de desenvolvimento do sistema de ensino, originando o que veio a ser denominado "Projeto Regional do Mediterrâneo" (PRM) (LEMOS, 2014, p. 78).

${ }^{6}$ Consultar: Capítulo 3 (Tecnocracia e Utilitarismo) e Capítulo 4 (Liberalismo e Tecnocracia).
} 
intervenção do Estado nas relações do mercado, defesa da livre e total concorrência, inviolabilidade da propriedade privada dos meios de produção, maximização da exploração da força de trabalho, da produtividade e dos lucros, interferindo diretamente nas políticas nacionais em todas as partes do mundo, exigindo o seu ajustamento à nova ordem econômica.

As políticas educacionais portuguesas que se encaminharam da segunda metade da década de 1970 para a primeira metade da década de 1980 foram marcadas por um contexto nacional de relativa "instabilidade, transformação e reconstrução social dos espaços educativos, encarados como exercício de uma cidadania promotora de uma cultura de direitos”, na qual a educação deveria contribuir, de forma coincidente, "para a formação da democracia legitimando-a no interior do próprio espaço educativo. Assim, a configuração das relações entre educação e democracia, ao pressuporem a construção da escola democrática, definiram o papel e a intervenção do Estado", entendido como a única instituição capaz de assegurar a liberdade democrática e o "respeito aos princípios da igualdade de oportunidades" (MENDONÇA, 2011, p. 22-23).

Nesses termos, o delineamento da educação como recurso fundamental para o desenvolvimento da democracia, assentada na existência de uma ordem política estável, produziu a emergência de uma preocupação focalizada na garantia da ordem educacional, mediante a regulação, regulamentação e gestão democrática das escolas, em que a obediência a um conjunto de regras previamente determinadas eram utilizadas para garantir a participação escolar e impedir qualquer possibilidade de desenvolvimento das ações sociais na educação.

A partir da segunda metade da década de 1980, observamos a existência de uma alternância gradativa na formulação e implantação das políticas educacionais em terras portuguesas - do mesmo modo na Espanha7 e no Brasil ${ }^{8}$

In: SANTOS, Flávio Reis. Capitalismo, tecnocracia e educação. Jundiaí/SP: Paco Editorial, 2015.

7 Educação Compensatória (Decreto Real n. 1.174/1983). Constituição dos Colégios Rurais Agrupados (Decreto Real n. 2.731/1986). 
-, diretamente relacionadas às questões que envolviam as contribuições da educação para a construção da democracia, imediatamente sucedidas pela emergência de preocupações com a eficiência, a eficácia e a qualidade da educação e do processo formativo para satisfazer as demandas do mercado de trabalho, priorizadas em relação aos aspectos ligados à autonomia da unidade escolar, da classe docente, ao currículo diversificado e democrático.

Na apreensão de Alice Mendonça (2011) o modelo de escola portuguesa resultante da Lei de Bases do Sistema Educativo (Lei n. 46, de 14 de outubro de 1986) não se restringiu às suas estruturas físicas, ou seja, à própria escola, anteriormente assimilada como uma comunidade escolar ampla que compreendia um conjunto de relações entre professores, pais, alunos, responsáveis pela educação, as instituições de poder e a comunidade local, por meio de um projeto educativo. Nesta direção, foram adotadas políticas para a educação9, dando à escola competências administrativas, pedagógicas, financeiras e culturais próprias, assentadas numa fundamentação neoliberal descentralizadora (desconcentradora) e regionalizadora.

Ana Benavente (1988, p. 24) de sua parte, infere que não podemos acreditar cegamente que a legislação por si só tem o poder para transformar as condições materiais concretas do processo de ensino e aprendizagem, visto que "a mudança da escola exige mudanças nas estruturas, nas relações e nas práticas de seus atores; mudar a legislação sem novas práticas não leva a mudanças significativas”. A legislação em sua abstração e frieza não é capaz de empreender mudanças substanciais no interior da escola sem considerar a efetiva participação e interveniência dos sujeitos que a fazem existir, levando em conta que a escola constitui mesmo, espaço de lutas responsável pela formação escolar e futuro profissional de centenas de milhares de crianças portuguesas.

\footnotetext{
${ }^{8}$ Constituição da República Federativa do Brasil (1988). Lei de Diretrizes e Bases da Educação Nacional (LDB n. 9.394/1996).

9 Decreto n. 43, de 3 de fevereiro de 1989 - dispunha sobre a autonomia da escola - e Decreto $\mathrm{n}$. 179, de 10 de maio de 1991, referente ao novo modelo de Direção, Administração e Gestão Escolar.
} 
As políticas neoliberais orientadas pela racionalização de recursos de todas as ordens, produziram consequências irreversíveis ao sistema educacional português e mais agudamente à escola, ou melhor dizendo à "não escola", uma vez que que o seu encerramento no meio rural cresceu acentuadamente a partir dos anos finais da década de 1980. A diminuição da importância e representatividade das escolas de $1^{0}$ ciclo no conjunto do sistema educacional repercutiu diretamente no modo de compreender politicamente e interferir (ou não) neste nível do ensino básico obrigatório, consubstanciando uma dupla exclusão daquelas pequenas escolas destinadas ao atendimento das populações rurais, visto que eram escolas isoladas em locais com processos contínuos de despovoamento, preterida em relação às escolas urbanas.

Abílio Amiguinho (2004, p. 148), argumenta que houve razões de sobra "para que se invocasse o carácter cada vez mais disperso da rede e da pequena dimensão de muitas escolas como duas questões estruturais do sistema educacional português" que, em realidade, não se traduziram "em medidas políticas que especificamente encarassem o problema prevalecendo sempre a incerteza e a suspeição sobre o futuro das mais pequenas unidades escolares" no meio rural.

\section{A CONSTITUIÇÃO DA EDUCAÇÃO E DA ESCOLA RURAL COMO OBJETOS DE ESTUDO}

As pesquisas científicas sobre a temática educação e escola rurais em Portugal, apesar de terem recebido a atenção de alguns estudiosos das Ciências da Educação, ainda requerem maior empenho e dedicação do universo acadêmico, tendo em vista o enriquecimento das discussões, análises e reflexões sobre os contextos que as caracterizaram e caracterizam no interior do país. As questões, condições e situações que envolvem a escola rural têm constituído objeto de uma interpretação relativamente simplista - de acordo com as inferências de Rui Canário (2000, p. 127-128) -, pois consiste, de um lado, no 
aprofundamento de sua dinâmica interna em relação ao sistema educacional, "omitindo a sua dimensão societal global"; e, de outro lado, exprime o "privilégio da dimensão meramente técnica da questão, reduzindo-a a um problema de maior ou menor racionalidade da rede escolar, encarada numa perspectiva de eficácia, de qualidade e de racionalização de custos”.

Foi somente a partir da segunda metade da década de 1970 que a educação passou a receber atenção do universo acadêmico português enquanto objeto de pesquisa, sendo consideráveis e relevantes os apontamentos de pesquisadores que se dedicaram a discutir a questão. $\mathrm{O}$ exame histórico e social acerca da educação para as populações rurais portuguesas durante a vigência do Estado Novo (1933-1974), indica uma justificativa baseada na tese da escola como fator de "hemorragia" ou de "sangria" do meio rural que, na concepção de Manuel Sarmento \& Joaquim de Oliveira (2005, p. 92) "a escola serviria basicamente para as crianças abandonarem a vontade de trabalhar a terra, de produzir na agricultura e, alternativamente, para ganhar a esperança e confiança de virem trabalhar para a cidade”.

A tese da "sangria" somente foi superada pela fundamentação ideológica do movimento fascista português, que defendia a educação para todas as comunidades rurais do país, afastando a concepção de que a escola extenua as localidades rurais de sua força de trabalho. Todavia, Manuel Sarmento, Tomé Sousa \& Fernando Ferreira (1998, p. 15) defendem que independente do contexto histórico-social há que se considerar que a educação rural se constituiu em estatuto de resistência às imposições tanto políticas quanto econômicas da sociedade capitalista, na medida em que afirma e reforça "a vitalidade das organizações educativas como instituições de produção e comunicação de saberes significativos para as crianças e sustentam a capacidade emancipatória da escola pública na promoção das culturas locais e no desenvolvimento comunitário".

Bártolo Campos (1993, p. 16) de sua parte ressalta, que o desenvolvimento das investigações nas Ciências da Educação em terras 
portuguesas, no decurso dos anos de 1970, se concentrou muito mais na dimensão do ensino do que da pesquisa, visto que o projeto político subentendido "era a formação de professores e não o fomento da investigação em educação" que, por longo tempo foi desconsiderada pelo Estado e por parte dos acadêmicos portugueses. Na mesma direção, António Nóvoa (1991, p. 48) argumenta que as pesquisas em educação foram tolhidas na sua "dimensão crítico-reflexiva pela urgência de uma ação quase desesperada em domínios vitais do sistema educativo", em especial, na "formação e profissionalização dos professores".

Joaquim Azevedo (1992, p. 78) por sua vez, infere que as investigações em educação não despertaram grande interesse da comunidade acadêmicocientífica portuguesa, parcos foram os investimentos no conhecimento da formação tecnológica, "área que parece ter tido impacto social assinalável na década de 1980". O desenvolvimento das pesquisas que amparam opções, ações e interveniências profissionais e políticas para o enriquecimento da produção de conhecimento nas Ciências da Educação demanda uma relação mais restrita entre a educação superior e a educação básica, entre pesquisadores e docentes.

Na apreensão de Ana Benavente (1992, p. 27), ao invés de um modelo de pesquisa em educação restrito e concentrado no contexto português, assentado em uma teoria de modernização precipitada em nível local, cuja produção do conhecimento é concebida relevante de forma automática e em que a investigação está a serviço do delineamento do sistema, buscava-se a realização de um modelo alternativo para a pesquisa em educação que na base da (re)definição da relação local-global pudesse possibilitar o desenvolvimento de uma investigação significativa e que a valorização das práticas e dos conhecimentos pudesse "responder à diversidade de interrogações e de pedidos sociais formulados à investigação em educação".

Segundo Renilton Cruz (2016), a década de 1980 exprimiu a expansão da educação superior em Portugal, marcadamente com a criação de vários programas de mestrado e de doutorado em Ciências da Educação, tendo em 
vista assegurar a formação e especialização dos profissionais docentes. Ao examinar e refletir sobre os estudos de José Pinto (1985) e de João Almeida (1999), Manuel Sarmento \& Joaquim de Oliveira (2005, p. 93), destacam o papel desempenhando pela escola no desenvolvimento do processo educativo no meio rural "como espaço de transição para a condição proletária dos filhos dos trabalhadores rurais", pois, na medida em que dissemina a cultura urbana para os rurícolas, "cria um conjunto de aspirações de mobilidade social, inculca junto às crianças as bases culturais e o habitus indispensável à criação da relação salarial, sendo, por consequência, o aparelho de Estado o indutor da modernização capitalista nos campos”.

Ao cruzar as fronteiras da pesquisa em educação para a pesquisa em educação rural localizamos poucos, mas, relevantes investigações desenvolvidas por estudiosos portugueses no decorrer dos anos 1990, como aqueles realizados por Raul Iturra (1990), ao chamar a atenção para um duro choque cultural entre os conhecimentos dominantes difundidos e reproduzidos pela escola e os conhecimentos populares dos rurícolas. Verificação reiterada por Sarmento \& Oliveira (2005, p. 93): "as crianças do campo procuram realidade na escola, sendo-lhes, em alternativa oferecida a fantasia de uma cultura distante dos contextos, dos valores, das diferenciações do seu cotidiano".

Também focalizados no embate cultural, Stephen Stoer \& Helena Araújo (1992) concentram as suas análises e reflexões na relação entre a escola e a comunidade contidas no universo do sistema capitalista de produção e na problemática relação entre as classes sociais e a cultura. Stoer \& Araújo (1992, p. 21 e 103), após analisarem "o choque potencial entre a expansão da escola urbana e a cultura rural no processo que conduz à integração do trabalhador rural na relação salarial" concluem que o processo de formação escolar voltado para a inserção no mercado de trabalho, significa de fato, "aprender a sobreviver numa economia clandestina ou aprender a viver com a frustração de um sonho nunca realizado".

Como resultado de investigações empíricas realizadas no interior dos 
programas de mestrado e doutorado em Ciências da Educação, bem como decorrentes da elaboração e implementação de projetos de intervenção educativas, importantes estudos foram publicados na década de 1990, conforme destaca Renilton Cruz (2016):

\begin{abstract}
Amiguinho, Canário, \& D’Espiney (1994) e Canário (1995), que sem negligenciar a questão da rede escolar, afirmam que a problemática da escola rural não se reduz à gestão ou à administração, pois essas dimensões da questão devem ser colocadas no interior da complexidade que envolve o desenvolvimento rural. Para os autores, a crise da escola reflete a crise do modelo de desenvolvimento imposto ao meio rural nas últimas décadas. Também merece relevo o trabalho de Formosinho (1998) que, no sentido contrário ao dos autores citados acima, discute a crise da escola rural no seio do problema da rede escolar, onde a solução passa pelo incremento de ações administrativas e organizacionais (CRUZ, 2016, p. 239).
\end{abstract}

Manuel Sarmento, Tomé Sousa \& Fernando Ferreira (1998) chamavam a atenção para a necessidade de maior atenção e desenvolvimento de mais pesquisas dedicadas à educação e a escola no meio rural, afirmando que tais objetos constituíam um não assunto na agenda investigativa do universo acadêmico português, excetuando-se alguns estudos naqueles tempos, voltados para a observação da crise geral da educação rural, "interpretada em função das movimentações e alterações demográficas, emergindo as questões da rede escolar e dos seus nós como tema de preocupação coletiva e de atenção nos meios educacionais e políticos" (AZEVEDO, 1996 apud SARMENTO; OLIVEIRA, 2005, p. 95).

Dezessete anos após as afirmações e apontamentos de Sarmento, Sousa \& Ferreira, mediante consulta ao Repositório Científico de Acesso Aberto de Portugal (RCAAP), Renilson Cruz (2016) analisou o estado da arte sobre educação e escola rural concentrado em dissertações e teses defendidas em Ciências da Educação no período de 1999 a 2014 nas Instituições de Educação Superior (IES) em Portugal, obtendo os seguintes resultados: 54 dissertações de mestrado e 3 teses de doutorado que abordavam direta e/ou indiretamente as 
questões sobre a educação e as escola rural em terras portuguesas (Tabela 1).

Tabela 1 - Dissertações e teses sobre educação/escola rural em Portugal (2000-2014).

\begin{tabular}{|c|c|c|}
\hline DESCRIÇÃO & DISSERTAÇÃO & TESE \\
\hline Escola Superior de Educação de Lisboa & 1 & o \\
\hline Instituto Politécnico de Bragança & 1 & o \\
\hline Instituto Politécnico de Lisboa & 1 & o \\
\hline Instituto Politécnico de Portalegre & 2 & o \\
\hline Universidade Aberta & 3 & o \\
\hline Universidade Católica Portuguesa & 2 & o \\
\hline Universidade da Beira Interior & 1 & o \\
\hline Universidade da Madeira & 3 & o \\
\hline Universidade de Aveiro & 2 & o \\
\hline Universidade de Coimbra & 2 & o \\
\hline Universidade de Lisboa & 5 & 1 \\
\hline Universidade de Trás-os-Montes e Alto Douro & 2 & o \\
\hline Universidade do Algarve & 1 & o \\
\hline Universidade do Minho & 11 & 2 \\
\hline Universidade do Porto & 6 & o \\
\hline Universidade Lusófona de Humanidades e Tecnologias & 2 & o \\
\hline Universidade Nova Lisboa & 1 & o \\
\hline Universidade Portucalense & 5 & o \\
\hline Universidade Superior de Psicologia Aplicada & 3 & o \\
\hline Totais & 54 & 3 \\
\hline
\end{tabular}

Fonte: Cruz (2016) - adaptação dos autores (2018). 
Os dados da Tabela 1 reiteram a relativa invisibilidade do universo rural e de suas realidades para a pesquisa científica nas universidades do país, visto que além da insuficiência de investigações em níveis de mestrado e doutorado, se verifica também, por meio de investigação empreendida por Renilton Cruz (2016) nos planos de curso e de ensino na Licenciatura em Educação das mais importantes universidades portuguesas uma inexistência de especificações curriculares que apontem para:

[...] um debate mais específico sobre a realidade educativa dos habitantes do meio rural. Embora a maioria dos cursos possuam unidades curriculares focadas na Intervenção Comunitária e Desenvolvimento Local, na Animação Socioeducativa, na Educação e Multiculturalidade, a presença de referência bibliográfica obrigatória ou sugerida ligada à educação ou escola do meio rural é profundamente escassa. Talvez na frágil exposição do problema nos cursos de formação inicial dos docentes resida um dos fatores que explicam a ainda pequena produção de investigações nos ciclos de estudos posteriores (CRUZ, 2016, p. 242).

Não podemos deixar escapar aqui, a importância das ações e atividades empreendidas pelo Instituto das Comunidades Educativas (ICE) - Organização não Governamental de âmbito nacional -, responsável por relevantes publicações sobre a educação e a escola para as populações que habitam no meio rural, que possui por propósito primeiro "o combate contra a exclusão social, a promoção da cultura educativa e o desenvolvimento local em Portugal". Fundado em 15 de julho de 1992 em decorrência da convergência de "projetos de intervenção, envolvimento e articulação de autarquias, coletividades, associações, escolas, universidades, serviços públicos e personalidades ligadas à cultura e à educação portuguesas" (ICE, 2017, p. 1).

Todavia, a ausência ou a pequena existência, ocorrência, incidência de discussões acadêmico-científicas que consideram a importante função da educação e o protagonismo da escola para as comunidades rurais pouco contribui interna e externamente para as populações que há muito tempo 
enfrentam as mais diversas dificuldades e discriminações em relação à valorização do urbanocentrismo. Uma reafirmação do distanciamento do universo acadêmico sobre os debates que envolvem a educação rural e a escola rural é verificada por meio de sondagem realizada junto a 6 dos mais importantes periódicos científicos na área de Ciências da Educação sob a responsabilidade de Instituições de Educação Superior em Portugal.

Tabela 2 - Publicações em periódicos portugueses sobre educação/escola rural (1999-2018).

\begin{tabular}{|c|c|c|c|c|}
\hline PERIÓDICO & $\begin{array}{c}\text { PERÍODO E } \\
\text { PERIODICIDADE }\end{array}$ & IES & $\begin{array}{c}\text { ARTIGOS } \\
\text { PUBLICADOS }\end{array}$ & $\begin{array}{c}\text { EDUCAÇÃO } \\
\text { E ESCOLA } \\
\text { RURAIS }\end{array}$ \\
\hline $\begin{array}{l}\text { Revista } \\
\text { Interacções }\end{array}$ & $\begin{array}{c}2005 \text { a } 2018 \\
\text { Quadrimestral }\end{array}$ & $\begin{array}{l}\text { Instituto } \\
\text { Politécnico de } \\
\text { Santarém } \\
\text { (Escola Superior } \\
\text { de Educação) }\end{array}$ & 484 & 2 \\
\hline $\begin{array}{l}\text { Revista } \\
\text { Portuguesa de } \\
\text { Pedagogia }\end{array}$ & $\begin{array}{c}1999 \text { a } 2018 \\
\text { Semestral }\end{array}$ & $\begin{array}{l}\text { Universidade de } \\
\text { Coimbra } \\
\text { (Faculdade de } \\
\text { Psicologia e } \\
\text { Ciências da } \\
\text { Educação) }\end{array}$ & 477 & O \\
\hline $\begin{array}{l}\text { Revista } \\
\text { Lusófona de } \\
\text { Educação }\end{array}$ & $\begin{array}{c}2003 \text { a } 2018 \\
\text { Semestral }\end{array}$ & $\begin{array}{l}\text { Universidade } \\
\text { Lusófona de } \\
\text { Humanidades } \\
\text { (Centro de } \\
\text { Estudos } \\
\text { Intervenção em } \\
\text { Educação) }\end{array}$ & 375 & 1 \\
\hline $\begin{array}{l}\text { Revista } \\
\text { Portuguesa de } \\
\text { Educação }\end{array}$ & $\begin{array}{c}1999 \text { a } 2018 \\
\text { Semestral }\end{array}$ & $\begin{array}{l}\text { Universidade do } \\
\text { Minho (Instituto } \\
\text { de Educação) }\end{array}$ & 330 & 2 \\
\hline $\begin{array}{l}\text { Educação, } \\
\text { Sociedade \& } \\
\text { Culturas }\end{array}$ & $\begin{array}{c}1999 \text { a } 2018 \\
\text { Semestral }\end{array}$ & $\begin{array}{l}\text { Universidade do } \\
\text { Porto } \\
\text { (Faculdade de } \\
\text { Psicologia e } \\
\text { Ciências da }\end{array}$ & 328 & 5 \\
\hline
\end{tabular}




\begin{tabular}{l|c|l|c|c}
\hline PERIÓDICO & $\begin{array}{c}\text { PERÍODO E } \\
\text { PERIODICIDADE }\end{array}$ & IES & $\begin{array}{c}\text { ARTIGOS } \\
\text { PUBLICADOS }\end{array}$ & $\begin{array}{c}\text { EDUCAÇÃO } \\
\text { E ESCOLA } \\
\text { RURAIS }\end{array}$ \\
\hline $\begin{array}{l}\text { Revista } \\
\text { Aprender }\end{array}$ & $\begin{array}{c}\text { 1999 a } 2018 \\
\text { Anual }\end{array}$ & $\begin{array}{l}\text { Escola Superior } \\
\text { de Educação de } \\
\text { Portalegre }\end{array}$ & 223 & 16 \\
\hline Totais & & & $\mathbf{2 . 2 1 7}$ & $\mathbf{2 6}$ \\
\hline
\end{tabular}

Fonte: elaboração dos autores (2018).

As informações contidas na Tabela 2 fornecem boa compreensão sobre os estudos empreendidos por pesquisadores portugueses sobre a educação/escola rural, caracterizando o real afastamento da academia com a temática que, ainda, não se constituiu, de fato, em área de investigação consistente em terras portuguesas. Rui Canário (2000) argumenta que as pesquisas em Ciências da Educação encontram-se sistematicamente subordinadas às políticas públicas do Estado e possuem um caráter gestionário, configurando tanto a educação quanto a escola no meio rural em temáticas periféricas e marginais das atividades de pesquisa acadêmico-científicas. $\mathrm{O}$ desprezo da escola rural "como objeto de estudo não decorre apenas do seu carácter periférico ou obsoleto que poria em causa a pertinência e o interesse de uma tal atividade. Para alguns investigadores, o que está em causa é a negação da própria existência da escola primária no meio rural" (CANÁRIO, 2000, p. 122).

Ainda de acordo com Canário (2000, p. 128), a problemática da educação e da própria escola para as populações que residem no meio rural, por suas implicações sociais e culturais constitui um excelente objeto de investigação e análise em que se destaca "a distinção entre uma visão técnica e gestionária dos problemas educativos e uma visão que recoloca a questão educativa no centro do debate político e filosófico, na continuidade da tradição tão bem representada por Paulo Freire", na qual projeto educativo e projeto 
político constituíam concretudes inseparáveis.

Justino Magalhães (2013, p. 63-64) por seu turno afirma que a relação forjada pela escola com a sociedade portuguesa "foi qualitativamente diferenciada e o rural foi representado como arcaico, subdesenvolvido e de inevitável transformação por contraponto ao mundo urbano culto e progressista”. No entendimento de Abílio Amiguinho (2008), o verdadeiro problema das escolas nas comunidades rurais portuguesas localiza-se em sua subordinação a uma concepção demasiadamente conservadora da própria escola rural, da própria educação para as comunidades rurais, do próprio desenvolvimento das localidades rurais, visto que:

[...] negam-se as suas características de escola, ou a sua existência, dada a forma como se considera que estas estruturas subvertem os princípios, as normas e as práticas da instituição e da organização escolar, historicamente, consolidados: o número de alunos é reduzido, as classes são heterogéneas em níveis e idades, os professores são poucos, a sua gestão é desnecessária [...]; subestimam-se modos de educação, socialização e de formação das crianças que povoam o quotidiano em meio rural [...]; pressupõe-se que as pequenas escolas são um obstáculo ao desenvolvimento porque disseminam recursos e investimentos, que é necessário concentrar para que se tornem produtivos. Por outro lado, porque se considera que as pequenas escolas não contam como polos ou instâncias por onde deve passar o desenvolvimento das zonas rurais mais sensíveis, articuladamente e em parceria com outras estruturas, particularmente quando, como é o caso, estas escasseiam em meio local (AMIGUINHO, 2008, p. 12-13).

Seja qual for o entendimento dentre os três apontados no fragmento acima, fato é que decorrem diretamente de proposições de desenvolvimento que já exprimiram as suas consequências mais malignas que, lamentavelmente, insiste e persiste na forma mais conservadora possível, originando processos e práticas que focalizaram benesse e intensificaram as desigualdades econômicas, sociais e territoriais, pois eliminaram do processo as instituições e os sujeitos das comunidades locais, fomentaram o esvaziamento do meio rural e reduziram drasticamente as densidades locais (AMIGUINHO, 2008). 
A escola de pequena dimensão do e no meio rural, de acordo com João Formosinho (1998), é caracterizada por sua pequena quantidade de alunos, poucos recursos, edificações físicas degradadas, situadas em comunidades isoladas, que acaba por ser considerada um entrave para a preconizada modernização da escola primária disposta nas políticas públicas educacionais deterministas que emanam das instituições multinacionais internacionais neoliberais. Nesses termos, qualquer avaliação que por ventura realizemos sobre o processo desenvolvimentista do mundo na atualidade, expressa a verdade de que o controle que detemos sobre a evolução da civilização em sentido amplo é frustrantemente limitado e, "portanto - argumenta João Formosinho (1998, p. 55) -, é possível que estejamos a induzir uma iniciação à escola que não prepara as crianças para a inevitabilidade da vida num mundo urbano".

Contudo, não podemos deixar de considerar que as diversas e diferentes atividades realizadas no interior das pequenas escolas rurais, que contam em maior ou menor incidência com o envolvimento das comunidades locais, são fundamentais para o desenvolvimento de ambas. Portanto, é perfeitamente possível encontrar na educação praticada na pequena escola para as populações que habitam no universo rural práticas educativas de resistência, que "afirmam a vitalidade das organizações educativas como instituições de produção e comunicação de saberes significativos para as crianças e sustentam a capacidade emancipatória da escola pública na promoção das culturas locais e no desenvolvimento comunitário" (SARMENTO; SOUSA; FERREIRA, 1998, p. 15).

Ao considerar a realidade atual da educação portuguesa, Alda Palmeiro (2011, p. 120) nos chama a atenção e aponta o crescimento do fechamento das escolas no universo rural, ocorrência que provoca o aumento do número de crianças que se vê obrigado a se deslocar diariamente de sua casa para frequentar o ensino básico, assim como "são maiores as distâncias entre os locais de residência e a escola, maior distância relacional entre as famílias e a escola, o contributo para o despovoamento, envelhecimento, corte da relação 
inter-geracional e abandono dos lugares e aldeias rurais".

José Maria Azevedo (1996, p. 111) reafirma as concepções expostas por Sarmento, Sousa \& Ferreira (1998) ao argumentar que "mais de que elemento de construção e reforço da identidade local por via da sua ação pedagógicocultural, a escola das pequenas povoações rurais é um instrumento de afirmação, um sinal de pertença, um raro benefício de que não se prescinde sem resistência”. Manuel Sarmento \& Joaquim Oliveira (2005) também defendem a educação para as populações rurais como forma de resistência à urbanização e à mercadorização, que se fazem dominantes em decorrência da globalização, sustentada por uma concepção de educação à serviço do desenvolvimento econômico capitalista e, por extensão, de desenvolvimento do universo rural. Os autores explicam que tal concepção é tributária de uma ideia de projeto das escolas rurais como:

[...] um movimento que é simultaneamente movimento pedagógico, movimento social, um movimento que se inclina para o desenvolvimento local, para a renovação das práticas educacionais, para a inovação e, ainda que isto seja paradoxal, para uma certa padronização de formas inovatórias de pedagogia em meio rural, algo como a conservação da tradição de inovação, em alternativa aos modelos hegemônica globais, o que tem profundas implicações, quer de natureza social, quer pedagógica, quer epistemológica, quer política (SARMENTO; OLIVEIRA, 2005, p. 96).

A educação rural deve ser entendida, de acordo com as concepções de Rui Canário (2000, p. 136), "como inscrita num ciclo vital que coincide com um processo de educação permanente" que, por seu turno, coincide "com um processo largo e multiforme de socialização que integra momentos e processos deliberados e não deliberados de ação educativa, que se torna questão indissociável da relação com o saber e só nestes termos é pertinente a sua discussão". Rui Canário (2000, p. 137) afirma ainda, que é por meio da "síntese entre as dimensões sociais da ação educativa e as dimensões educativas da ação social que se torna possível fazer coincidir um projeto educativo globalizado 
com um projeto globalizado de desenvolvimento local”.

\section{CONSIDERAÇÕES FINAIS}

No decurso do século XX, o universo rural foi submetido a diversas transformações nas mais diferentes regiões do mundo. Nos países desenvolvidos as mudanças decorreram de forma mais efetiva do próprio processo de desenvolvimento da indústria, da expansão urbana e de um robusto crescimento do comércio. Analogamente, o meio rural perdeu significado e importância e foi transformado em sua existência, em seus costumes, em suas tradições, em suas culturas para dar espaço a um crescimento econômico direcionado para um propósito único: aumento da produção e da produtividade com racionalidade e racionalização. Os países "subdesenvolvidos", em "vias de desenvolvimento", "periféricos", por sua vez, expressaram a sua essência por meio de uma economia fundamentalmente agrícola e a ruralidade gradativamente entendida como sinônimo de atraso, pobreza e paladina das discrepâncias sociais e da supremacia do capital internacional.

Portugal em tal contexto, enxergava o universo rural como aquele que abrigava a maior parte da população e que tinha uma diversidade econômica paulatinamente bem diferenciada entre o Portugal Rural, o Portugal Litorâneo e o Portugal Urbano, por outra parte, o Estado português não admitia uma diferenciação da educação diante das significativas diferenças de realidade e existência entre o rural e o urbano. A relação entre a educação rural com a escola rural em Portugal, "reporta a comunalidades e contrastes que resultam dos quadros histórico-pedagógicos e, também, das indeterminações políticoideológicas, quer por parte dos regimes republicanos e democráticos, quer por parte dos governos centralizadores e totalitários - Estado Novo" (MAGALHÃES, 2018, p. 294).

Não houve homogeneidade e nem tão pouco prosseguimento de uma 
concepção científico-pedagógica do universo rural como expressão de uma realidade significativa para a existência e equilíbrio da sociedade no mundo contemporâneo. $\mathrm{O}$ que de fato estava em questão era a própria destinação histórica do universo rural e sua relação com a educação e a escola para as populações rurais. O letramento, alfabetização, formação escolar, certificação escolar constituía uma possibilidade de transformação social e econômica que, de uma forma ou de outra, contribuiu para o esvaziamento das áreas rurais. $\mathrm{O}$ modelo de desenvolvimento histórico português produziu "um alinhamento e uma secundarização do rural frente ao urbano, da agricultura frente à indústria, da total substituição da economia de troca pela mercantilização" (MAGALHÃES, 2018, p. 295).

Ao questionarmos qual é a educação que precisa e deve ser destinada às populações que vivem no meio rural, qual a perspectiva de existência futura da escola no meio rural significa, primeiramente, questionar qual o futuro do próprio universo rural, "repensando modelos de sociedade e de desenvolvimento [que permanecem] dominantes. Apressadamente condenada por alguns, em nome de uma certa ideia de progresso, a escola rural pode emergir como um polo de desenvolvimento local e de renovação das práticas educativas" (CANÁRIO, 1996, p. 129).

As imposições que incidiram sobre as escolas de pequena dimensão no universo rural foram, permanentemente, solicitadas para exprimir a impossibilidade ou a inutilidade de sua existência e manutenção. O sistemático fechamento das escolas para as populações em áreas rurais, no meio rural, no universo rural tem sido justificado pelas políticas neoliberais da UNESCO, da OCDE e demais instituições multilaterais internacionais a serviço e em defesa do capital, mais especificamente do grande gestor das políticas públicas de educação nos países da periferia do capital: o Bando Mundial. Simplificar "o problema" da existência, permanência e manutenção da escola rural à mera racionalização do sistema e da rede escolar representa a plena abdicação da compreensão da complexidade "de uma situação problemática que não decorre 
do decréscimo do número de alunos, mas de sua relação com o carácter periférico das zonas rurais, com suas perdas demográficas, com as baixas taxas de escolarização, com a ausência de emprego, com a perda de identidade" (CANÁRIO, 2000, p. 137-138).

O fechamento das escolas para as populações em áreas rurais, no meio rural, no universo rural tem sido justificado pelas políticas neoliberais da Unesco, OCDE e demais instituições multilaterais internacionais a serviço e em defesa do capital e, mais especificamente, do grande gestor das políticas públicas de educação nos países da periferia do capital: o Bando Mundial. Simplificar "o problema" da existência, permanência e manutenção da escola rural à mera racionalização do sistema e da rede escolar representa a plena abdicação da compreensão da complexidade de um problema que não se resume à demanda de estudantes, mas à sua relação direta e indireta com as características locais das comunidades rurais, com baixos índices de formação escolar institucionalizada, mínimas possibilidades de colocação no mercado de trabalho, reterritorialização, aculturação diante das transformações imposta pelo sistema capitalista de produção, em especial, a substituição de grande contingente de trabalhadores por máquinas.

Entendemos que tais políticas põem termo a uma dinâmica de funcionamento setorial alinhada à possibilidades de desenvolvimento, na qual a relação com a educação se materializa na medida proporcional em que as determinações econômicas são preponderantes "e as finalidades da educação se confundem com crescimento econômico" e, de outra parte, "põem a descoberto a supremacia do modelo escolar no campo educativo sem assegurar as condições para um desenvolvimento rural em que a educação no seu sentido mais vasto venha contribuir para o bem-estar das populações que permanecem no meio rural" (SARMENTO; OLIVEIRA, 2005, p. 99). A existência, ou melhor, a insistência, a resistência das comunidades rurais em defesa da escola no meio rural, são imprescindíveis em termos civilizacionais. A reestruturação das escolas para as populações que habitam no meio rural pode contribuir 
substancialmente para a constituição de uma nova ruralidade em tempos de globalização, considerando sempre a sua imbricação e indissociabilidade ao universo maior, a sociedade capitalista.

A educação para as populações que habitam no meio rural precisa se constituir em atividades educativas de resistência em (re)afirmação do ímpeto das entidades educativas como instituições de efetiva produção de conhecimentos, substanciais para as comunidades locais, tendo em vista a prática e disseminação das culturas locais e desenvolvimento coletivo no universo rural (SARMENTO; SOUSA; FERREIRA, 1998). A educação destinada às populações rurais para além dos limites de recurso de identificação e reconhecimento das características econômicas, sociais, culturais e ambientais locais, constitui mesmo recurso de afirmação de pertencimento mediante à efetiva resistência aos ditames excludentes do capital internacional (AZEVEDO, 1996).

A educação para as populações rurais deve consubstanciar firme resistência à expansão da urbanização e à exclusiva mercadorização do resultado da produção rural (SARMENTO; OLIVEIRA 2005). A educação rural deve ser concebida imprescindivelmente como processo de educação permanente, compatibilizado com um processo lato e multiforme de socialização que possa reunir experiências e processos deliberados e não deliberados da ação educativa, intrínseco da relação com o conhecimento (CANÁRIO, 2000).

Ao considerar os apontamentos efetuados pelos pesquisadores abordados na presente revisão é possível especificar em sentido lato, que a sobre a educação para populações rurais precisa ter por fundamento central o reforço e reafirmação dos laços de pertencimento, de luta e de resistência das comunidade locais, mediante a construção e utilização estratégias específicas para promover e garantir o seu desenvolvimento socioeconômico e, nesta direção, combinar a luta entre a efetivação e ampliação do direito à educação e à escolarização no universo rural e a construção de uma escola que esteja no meio 
rural, que também seja do meio rural e que jamais se aparte da sociedade em sua mais ampla totalidade.

Para finalizar, em nossa concepção educação rural é aquela que decorre de forma direta e indireta da luta e da resistência empreendidas pelas populações rurais, orientada por uma concepção de emancipação individual e coletiva do trabalho em relação à sua subordinação ao capital, levando em conta a importação da intencionalidade de articular educação e trabalho, mediante a adoção de convicções estratégicos que contribuam para as práticas experiências formativas. Em nossa concepção, o enfrentamento é fundamental para resistir e combater ao desmedido e perverso expansionismo do capital em Portugal, na Espanha, no Brasil e nas mais diversas partes do mundo, pois, de outro modo não haverá educação para as populações que moram no meio rural.

\section{REFERÊNCIAS}

AMIGUINHO, Abílio José Maroto. A escola e o futuro do mundo rural. 2004. Tese (Doutoramento em Ciências da Educação, Área de Formação de Adultos) - Faculdade de Psicologia e de Ciências da Educação, Universidade de Lisboa, Lisboa, 2004.

AMIGUINHO, Abílio José Maroto. Um testemunho em torno da problemática e da intervenção na escola rural. In: Atas... Educação e meios rurais: problemas e caminhos do desenvolvimento. Lisboa: Conselho Nacional de Educação/Ministério da Educação, 1996. Disponível em: http://www.cnedu.pt/content/edicoes/seminarios_e_coloquios/educacaomeios-rurais.pdf. Acesso em: 14 dez. 2017.

AMIGUINHO, Abílio. Escola em meio rural: uma escola portadora de futuro? Educação, Santa Maria, v. 33, n. 1, jan./abr. 2008. Disponível em: https://periodicos.ufsm.br/reveducacao/article/view/16. Acesso em: 3 nov. 2017.

AMIGUINHO, Abílio. La escuela en el medio rural: educación y desarrollo local. Revista de currículum y formación del profesorado, v. 15, n. 2, 2011. Disponível em: https://www.ugr.es/ recfpro/rev152ART2.pdf. Acesso em: 3 
nov. 2017.

AZEVEDO, Joaquim. Ciências da educação e formação tecnológica e profissional. In: AMBRÓSIO, Teresa et al. Decisões nas políticas e práticas educativas. Porto: Sociedade Portuguesa de Ciências da Educação (SPCE), 1992.

AZEVEDO, José Maria. Os nós da rede: o problema das escolas primárias em zonas rurais. Porto: Edições Asa, 1996.

BENAVENTE, Ana. A escola na sociedade de classes. Lisboa: Horizonte, 1976.

BENAVENTE, Ana. As ciências da educação e a inovação das práticas educativas. AMBRÓSIO, Teresa et al. Decisões nas políticas e práticas educativas. Porto: Sociedade Portuguesa de Ciências da Educação (SPCE), 1992.

BENAVENTE, Ana. Da construção do sucesso escolar: equacionar a questão e debater estratégias. Seara Nova, Lisboa, n. 18, jun./jul. 1988. Disponível em: http://www.searanova.publ.pt/pt/?tpl=1128. Acesso em: 18 jan. 2018.

BENAVENTE, Ana. Insucesso escolar no contexto português: abordagens e concepções políticas. In: Atas... I Conferência nacional "Ciências da educação em Portugal: situação actual e perspectivas". Porto:

Sociedade Portuguesa de Ciências da Educação (SPCE), 1991.

BRASIL. Constituição da República dos Estados Unidos do Brasil, de 10 de novembro de 1937. Rio de Janeiro: Presidência da República, 1937. Disponível em: http://www2.camara.leg.br/legin/fed/consti/19301939/constituicao-35093-10-novembro-1937-532849-publicacaooriginal15246-pl.html. Acesso em: 4 jan. 2018.

CAMPOS, Bártolo Paiva. As ciências da educação em Portugal. Inovação, n. 6, 1993.

CANÁRIO, Rui. A escola no mundo rural: contributos para a construção de um objecto de estudo. Educação, sociedade \& cultura, n. 14, 2000. Disponível em: https://www.fpce.up.pt/ciie//revistaesc/ESC14/14-7-canario.pdf. Acesso em: 19 dez. 2017.

CARVALHO, Rómulo. História do ensino em Portugal desde a fundação da nacionalidade até ao fim do regime de Salazar-Caetano. 2. ed. Lisboa: Fundação Calouste Gulbenkian, 1996. 
CORTESÃO, Luiza. Escola, sociedade que relação? 2 ed. Porto: Afrontamento, 1988.

CRUZ, Renilton. A escola rural na produção acadêmica portuguesa: apontamentos sobre a (in)visibilidade de um objeto de estudo. Revista portuguesa de educação, Minho, n. 29, 2016. Disponível em: http://www.scielo.mec.pt/pdf/rpe/v29n2/v29n2a11.pdf. Acesso em: 18 out. 2017.

ESPAÑA. Ley general de educación y financiamiento de la reforma educativa. BOE n. 187 de 06 ago. 1970. Disponível em: http://www.boe.es/diario_boe/txt.php?id=BOE-A-1970-852. Acesso em: 12 out. 2017.

\section{ESPAÑA. Real Decreto n. 1.174, de 27 de abril de 1983, sobre}

Educación Compensatoria. BOE n. 112 de 11 mai. 1983. Disponível em: http://www.boe.es/diario_boe/txt.php?id=BOEA-1983-13484. Acesso em: 13 out. 2017.

\section{ESPAÑA. Real Decreto n. 2.731, de 24 de deciembre de 1986, sobre} Constituicion de Colegios Rurales Agrupados de Educación General Basica. Madrid: Ministerio de Educación, Cultura y Deporte, 1986. Disponível em: https://boe.vlex.es/vid/constitucion-colegios-rurales-agrupados-basica15515354\#articulo1.1. Acesso em: 8 jul. 2017.

FORMOSINHO, João. O ensino primário: de ciclo único do ensino básico a ciclo intermédio da educação básica. Cadernos PEPT 2ooo, Lisboa, Programa nacional de educação para todos, n. 21, 1998.

HEREDERO, Eladio Sebastián; GONZALEZ, Claudia Inés Collado; NOZU, Washington Cesar Shoiti. Los colegios rurales agrupados en España: analisis del funcionamiento y organización de la escuela rural española a partir de un estudio de casos. Educação e fronteiras online, Dourados/MS, v. 4, n. 12, set./dez. 2014. Disponível em:

http://ojs.ufgd.edu.br/index.php/educacao/article/view/4716/2499. Acesso em: 16 abr. 2017.

IANNI, Octavio. A era do globalismo. 3 ed. Rio de Janeiro: Civilização Brasileira, 1997.

ICE. Instituto das Comunidades Educativas. Quem somos. Setúbal, 2017. Disponível em: http://iceweb.org/. Acesso em: 4 jan. 2018.

ITURRA, Raul. Fugirás à escola para trabalhar a terra: ensaios de 
antropologia social sobre o insucesso escolar. Lisboa: Escher, 1990.

LEITE, Sérgio Celani. Escola rural: urbanização e políticas educacionais. 2. ed. São Paulo: Cortez, 2002.

LEMOS, Valter Victorino. A influência da OCDE nas políticas de educação em Portugal. 2014. 319 f. Tese (Doutorado em Políticas Públicas) Instituto Universitário de Lisboa, Lisboa, Portugal, 2014. Disponível em: https://repositorio.iscteiul.pt/bitstream/10071/8434/1/Tese\%2oValter\%2oLemos\%20\%28\%2B\%20ane xos\%20e\%20CV\%29.pdf. Acesso em: 18 jan. 2018.

LUNA, Rogeli Santamarina. Un poco de historia de la escuela rural en España. Escuela rural, España, 2010. Disponível em: http://escuelarural.net/IMG/pdf/UN_POCO_DE_HISTORIA_DE_LA_ESCU ELA_RURAL_EN_ESPANA.pdf. Acesso em: 16 jan. 2018.

MAGALHÃES, Justino. Escola única e educação rural no estado novo em Portugal. Historia y memoria de la educación, Laguna, v. 7, 2018. Disponível em: http://revistas.uned.es/index.php/HMe/article/view/18733. Acesso em: 3 nov. 2017.

MAGALHÃES, Justino. O rural e a escolarização em Portugal. Educação e filosofia, Uberlândia, v. 27, número especial, 2013. Disponível em: http://www.seer.ufu.br/index.php/EducacaoFilosofia/article/view/22688. Acesso em: 6 nov. 2017.

MENDONÇA, Alice. Evolução da política educativa em Portugal. Departamento de Ciências da Educação, Universidade da Madeira, 2011. Disponível em:

http://www3.uma.pt/alicemendonca/conteudo/investigacao/evolucaodapolitic aeducativaemPortugal.pdf. Acesso em: 15 jan. 2018.

NÓVOA, António. As ciências da educação e os processos de mudança. In: Ciências da educação e mudança. Porto: Sociedade Portuguesa de Ciências da Educação (SPCE), 1991.

PALMEIRO, Alda Marília dos Santos. Autarquias e escolas em meio rural. 2011. 238 f. Dissertação (Mestrado em Formação de Adultos e Desenvolvimento Local) - Instituto Politécnico de Portalegre, Escola Superior de Educação, Portalegre, 2011. Disponível em:

https://comum.rcaap.pt/bitstream/10400.26/8398/1/Alda\%20Mar\%C3\%ADli a\%20dos\%2oSantos\%2oPalmeiro.pdf. Acesso em: 2 out. 2017. 
PORTUGAL. Decreto n. 13:619, de 17 de maio de 1927. Lisboa: Ministério da Instrução Pública/Direcção Geral do Ensino Primário e Normal, 1927.

Disponível em: http://193.137.22.223/fotos/editor2/1927.pdf. Acesso em: 9 jan. 2018.

PORTUGAL. Decreto n. 18:140, de 18 de março de 193o. Lisboa:

Ministério da Instrução Pública/Direcção Geral do Ensino Primário e Normal, 1930. Disponível em: http://193.137.22.223/fotos/editor2/1930.pdf. Acesso em: 9 jan. 2018.

PORTUGAL. Decreto-Lei n. 40.964, de 31 de dezembro de 1956. Lisboa: Ministério da Educação Nacional, 1938. Disponível em: http://193.137.22.223/fotos/editor2/RDE/P/EP/EPri_1956_1964/index.html\# /4/. Acesso em: 9 jan. 2018.

PORTUGAL. Decreto-Lei n. 42.944, de 28 de maio de 1960. Lisboa: Ministério da Educação Nacional, 1938. Disponível em: http://193.137.22.223/fotos/editor2/1960.pdf. Acesso em: 9 jan. 2018.

PORTUGAL. Decreto-Lei n. 45.81o, de 9 de julho de 1964. Lisboa: Ministério da Educação Nacional, 1964. Disponível em: http://193.137.22.223/fotos/editor2/1964.pdf. Acesso em: 9 jan. 2018.

PORTUGAL. Decreto-Lei n. 48.546, de 27 de agosto de 1968. Lisboa: Ministério da Educação Nacional/Direcção Geral do Ensino Primário, 1968. Disponível em: http://193.137.22.223/fotos/editor2/1968_27_08.pdf. Acesso em: 9 jan. 2018.

PORTUGAL. Decreto-Lei n. 539, de 31 de dezembro de 1979. Lisboa: Presidência do Conselho de Ministros/Ministério da Educação 1979. Disponível em: http://193.137.22.223/fotos/editor2/1979.pdf. Acesso em: 9 jan. 2018.

PORTUGAL. Lei n. 1:969, de 20 de maio de 1938. Lisboa: Ministério da Educação Nacional, 1938. Disponível em:

http://193.137.22.223/fotos/editor2/1938.pdf. Acesso em: 9 jan. 2018.

PORTUGAL. Lei n. 46, de 14 de outubro de 1986. Lei de Bases do Sistema Educativo. Guimarães/Braga: Assembleia da República, 1986. Disponível em: http://193.137.22.223/fotos/editor2/1986.pdf. Acesso em: 10 dez. 2017.

SANTOS, Flávio Reis. Capitalismo, tecnocracia e educação: da utopia social saintsimoniana à economia (neo)liberal friedmaniana. Jundiaí/SP: Paco Editorial, 2015 . 
SANTOS, Flávio Reis; BEZERRA NETO, Luiz. Políticas públicas para a educação rural no Brasil: da omissão à regulamentação do Programa Nacional de Educação na Reforma Agrária. Histedbr On-line, Campinas, v. 15, n. 66, 2015. Disponível em:

https://periodicos.sbu.unicamp.br/ojs/index.php/histedbr/article/view/86437 09/11225. Acesso em: 2 fev. 2018.

SARMENTO, Manuel Jacinto; OLIVEIRA, Joaquim Marques. A escola é o melhor do povo: relatório de revisão institucional do projecto das escolas rurais. Porto: Profedições, 2005.

SARMENTO, Manuel Jacinto; SOUSA, Tomé Bahia; FERREIRA, Fernando Ilídio. Tradição e mudança na escola rural: estudo de caso. Lisboa: Ministério da Educação/Departamento de Avaliação, Prospectiva e Planeamento, 1998.

SMITH, Adam. Riqueza das nações. São Paulo: Folha de S. Paulo, 2010.

STOER, Stephen; ARAÚJO, Helena Costa. A escola e a aprendizagem para o trabalho num país da (semi)periferia europeia. Lisboa: Escher, 1992.

WANDERLEY, Maria de Nazareth Baudel. A emergência de uma nova ruralidade nas sociedades modernas avançadas: o rural como espaço singular e ator coletivo. Estudos sociedade e agricultura, n. 15, 2000. Disponível em: http://r1.ufrrj.br/esa/V2/ojs/index.php/esa/article/view/178/174. Acesso em: 4 mar. 2016.

FLÁVIO REIS SANTOS é doutor em Educação pela Universidade Federal de São Carlos (UFSCar). Professor de Ensino Superior Doutor da Universidade Estadual de Goiás (UEG), atuando no Programa de Pós-Graduação StrictoSensu Ambiente e Sociedade e nos cursos de graduação em História, Geografia, Letras e Matemática. Professor Convidado nos cursos de PósGraduação Lato-Sensu em Gestão Escolar e Pós-Graduação Lato-Sensu em Programa de Apoio aos Dirigentes Municipais de Educação da Universidade Federal de São Carlos. Atualmente desenvolve pesquisas sobre a aplicação de fundamentos tecnocráticos na formulação de políticas públicas de educação e sobre políticas públicas de educação para os sujeitos do campo.

E-mail: reisdossantos.flavio@gmail.com

(ib) https://orcid.org/0000-0003-1538-1208 
MAGDA VALÉRIA SILVA é doutora em Geografia pela Universidade Federal de Uberlândia (Instituto de Geografia/UFU). Mestre em Geografia pela Universidade Federal de Goiás (Instituto de Estudos Socioambientais/UFG). Professora do Programa de Pós-Graduação em Geografia da Universidade Federal de Goiás - Regional Catalão (PPGGC/UFG). Professora Colaboradora do Programa de Pós-Graduação em Ambiente e Sociedade da Universidade Estadual de Goiás (PPGAS/UEG). Coordenadora do Núcleo de Estudos e Pesquisas Geografia, Ensino, Espaço Urbano e Ação (Geeuação).

E-mail: magdaufgcatalao@yahoo.com.br

(1) https://orcid.org/0000-0003-2808-6144

Recebido em: 19 de outubro de 2018

Aprovado em: 06 de maio de 2019

Revista História da Educação - RHE

Associação Sul-Rio-Grandense de Pesquisadores em História da Educação - Asphe

Artigo de acesso aberto distribuído nos termos de licença Creative Commons. 